This is the accepted version of the following article:

Fuentes S., Muñoz P., Llanos J., Vega M., Martin I.R., Chavez-Angel E.. Synthesis and optical characterization of Er-doped bismuth titanate nanoparticles grown by sol-gel hydrothermal method. Ceramics International, (2017). 43. : 3623 - . 10.1016/j.ceramint.2016.11.200,

which has been published in final form at https: //dx.doi.org/10.1016/j.ceramint.2016.11.200 @ https://dx.doi.org/10.1016/j.ceramint.2016.11.200. This manuscript version is made available under the CC-BY-NC-ND 4.0 license http://creativecommons.org/licenses/by-nc-nd/4.0/ 


\title{
Synthesis and optical characterization of Er-doped bismuth titanate nanoparticles grown by sol- gel hydrothermal method
}

\author{
$\underline{\text { S. Fuentes }}^{*}$,e,, P. Muñoz ${ }^{\mathrm{a}}$ J. Llanos ${ }^{\mathrm{b}}$, M. Vega ${ }^{\mathrm{b}}$, I.R. Martin ${ }^{\mathrm{c}}$ and $\underline{\text { E. Chavez-Angel }}^{{ }^{\mathrm{d}}}$ \\ aDepartamento de Ciencias Farmaceúticas, Facultad de Ciencias, Universidad Católica del Norte, Antofagasta, \\ Chile. \\ bDepartamento de Química, Facultad de Ciencias, Universidad Católica del Norte, Antofagasta, Chile. \\ 'Departamento de Física Fundamental, Experimental, Electrónica y Sistemas, Universidad de La Laguna, 38206 \\ La Laguna, Tenerife, Spain. \\ ${ }^{\mathrm{d} I n s t i t u t e}$ of Physics, University of Mainz, Staudinger Weg 7, 55128 Mainz, Germany. \\ ${ }^{\mathrm{e}} \mathrm{Center}$ for the Development of Nanoscience and Nanotechnology, CEDENNA, Santiago, Chile.
}

\begin{abstract}
The $\mathrm{Er}^{3+}$-doped bismuth titanate $\left(\mathrm{Bi}_{4} \mathrm{Ti}_{3} \mathrm{O}_{12}, \mathrm{BIT}\right)$ nanoparticles were synthesized by a combined sol-gel and hydrothermal method under a partial oxygen pressure of 30 bar. The composition and morphology were characterized by x-ray diffraction (XRD), scanning electron microscopy (SEM) and Raman scattering. They showed pure and homogeneous spherical BIT nanoparticles with a size below the 40 $\mathrm{nm}$. The incorporation of Er ions showed a strong decrease in the lattice parameters, as well as averaged particle size. The reduction of the particle size also led to a stabilization of a pseudo-tetragonal phase with lattice parameter $a=b \approx \sqrt{2} a_{T}$, where $a_{T}$ is the lattice parameter of the high-temperature tetragonal phase of BIT. The photoluminescence up-conversion (excitation wavelength $=1480 \mathrm{~nm}$ ) showed an enhancement of the infrared emission $(980 \mathrm{~nm})$ as Er concentration increased, achieving a maximum for $6 \% \mathrm{~mol}$, while photoluminescence spectra (excitation wavelength $=473 \mathrm{~nm}$ ) showed a strong green emission (529 and $553 \mathrm{~nm}$ ) with a maximum at $4 \% \mathrm{~mol}$.
\end{abstract}

Keywords: Oxide materials; Sol-gel processes; Hydrothermal; Photoluminescence.

\footnotetext{
Corresponding authors:

*sfuentes@ucn.cl

†cemigdio@uni-mainz.de
} 


\section{Introduction}

Bismuth titanate $\left(\mathrm{Bi}_{4} \mathrm{Ti}_{3} \mathrm{O}_{12}, \mathrm{BIT}\right)$ is a member of Aurivillius-type bismuth-layered perovskite oxides, with a general formula $\left(\mathrm{Bi}_{2} \mathrm{O}_{2}\right)\left[A_{m-1}(B)_{m} O_{3 m+1}\right]$. In this notation A represents a mono-, bi- or trivalent ion, $\mathrm{B}$ denotes a tetra-, penta- or hexavalent ion, and $m$ is the number of $\mathrm{BO}_{6}$ octahedra in each pseudoperovskite block $(m=1,2,3, \ldots)$, where $m=3$ for BIT compounds. The crystallographic structure consists of a layered arrangement of three perovskite-like cells of $\left(A_{m-1}(B)_{m} O_{3 m+1}\right)^{2-}$ embedded between two bismuth oxides layers $\left(\mathrm{Bi}_{2} \mathrm{O}_{2}\right)^{2+}$ along the c-axis [1,2]. It is widely accepted that the $\mathrm{Bi}_{2} \mathrm{O}_{2}$ layers have a very important influence on the properties of bismuth layer-structured ferroelectrics (BLSFs), as the $\mathrm{Bi}_{2} \mathrm{O}_{2}$ layers act as insulating layers and are self-regulated to compensate for space charge due to their net electric charge [3]. This configuration favours outstanding ferroelectric properties, and, as a consequence, it has drawn extensive the attention from the scientific community as one of the most promising candidates to replace the lead-based ceramics.

Due to its low dielectric constant, high Curie temperature and strong anisotropy of the spontaneous polarization, such materials can be used in a broad range of applications, including but not limited to: piezoelectric, dielectric, pyroelectric, electrooptic, antennas, photocatalytic and biosensing fields, as well as potentially optical-electrical integrated and coupling devices [4-8]. However, its high dielectric loss, small remnant polarization and low fatigue-resistance limit its performance in other applications such as ferroelectric random access memory, FRAM, for example [9].

Recent studies have revealed that the rare-earth ion substitution in the A-site of perovskite structures can effectively overcome such drawbacks $[10,11]$. Park et al. reported fatigue-free, excellent ferroelectrical properties of BIT films doped with $\mathrm{La}^{3+}$ ions [12]. Improved results were obtained by Kim et al. through $\mathrm{Nd}^{+3}$ doping in BIT films [13]. The fatigue-free behaviour of these films can be attributed to the enhanced stability of oxygen in the Ti-O octahedron layer, which is caused by the substitution of stable rare-earth ions for volatile $\mathrm{Bi}$ ions located near the Ti-O octahedron layer. The enhancement of the ferroelectric properties can be explained by the fact that the substitution of $\mathrm{Bi}$ atoms by rare-earth ions, with different ionic radius, produces a structural distortion of the perovskite and, consequently, an enhancement of the remnant polarization [11]. 
On the other hand, the addition of the rare-earth ions with optical activity in the bismuth layer structure opens the possibility for use as a high-performance luminescent material, with a broad field of applications including opto- and microelectronics, as well as photon upconversion (UC) $[14,15]$. Nearinfrared to visible upconversion (UC) is an important approach for the generation of visible luminescence. The interest in UC emission has increased due to the need for all-solid compact laser devices and three-dimensional displays. Trivalent rare earth doping-ions such as $\mathrm{Pr}^{3+}, \mathrm{Ho}^{3+}, \mathrm{Tm}^{3+}, \mathrm{Nd}^{3+}$ and $\mathrm{Er}^{3+}$ are used as emission centers in UC materials [16-18].

Among the lanthanide ions, $\mathrm{Er}^{3+}$ is found to be the most effective dopant for UC emission, and the metastable levels ${ }^{4} \mathrm{I}_{9 / 2}$ and ${ }^{4} \mathrm{I}_{11 / 2}$ of $\mathrm{Er}^{3+}$ can be conveniently populated using low cost, low power laser diodes operating at 800 and $980 \mathrm{~nm}$ [18]. The search for suitable host materials is gaining importance for realizing high UC efficiency in the visible and the mid-IR region. Various host-material dependent factors such as phase purity, particle size, Er doping content, site substitution, and rare earth ion interactions in the host matrix are found to influence the UC emission [19]. Appropriate host materials offering good thermal stability and sensitivity over a wide temperature range (below and above room temperature) are in demand especially for luminescence thermometry applications.

In recent years, different synthesis methods have been reported in the literature for the fabrication of BIT powders. The choice of synthesis process plays a crucial role in obtaining a BIT with specific microstructure control as well as purity and chemical homogeneity. The control of these parameters has a significant effect on dielectric, ferroelectric and optical properties. Among the most popular processes are solid-state reactions [20] and high-energy ball milling processes [21]. However, these methods present some drawbacks, such as: formation of secondary phases, contamination by impurities, high heat treatment temperatures, long processing times and non-uniform particle size distribution.

An effective way to overcome such drawbacks is through wet chemical or soft-chemistry method. These methods not only ensure a homogeneous phase and well-controlled particle size but also more complex architectures and improvement of the dielectrical, structural, morphological and mechanical properties of BIT oxides[18,22,23]. Some of the most popular methods include: sol-gel [19], citrate gel [24], urea precipitation [25], oxalate coprecipitation [26], hydrothermal [27-29], metal organic decomposition [30], polymeric precursor [31], and microwave [32], to name a few. Among these synthetic methods, 
hydrothermal or chemical reaction methods are of great interest, because they are safe and eco-friendly. The syntheses are performed at moderate temperatures, $\mathrm{T} \sim 200 \circ \mathrm{C}$. To the best of our knowledge, the influence of the atmosphere in the use of hydrothermal methods to prepare BIT and doped-BIT has not been yet reported in the literature.

In this work, we report on structure, surface morphology and UC luminescence properties of BIT materials doped with different $\mathrm{Er}^{3+}$ concentrations, synthesized by a combined sol-gel hydrothermal method in an oxygen atmosphere. The effects of $\mathrm{Er}^{3+}$ concentration on the UC emissions and their mechanisms are discussed.

\section{Experimental}

\subsection{Synthesis}

$\mathrm{Bi}_{4-x} \mathrm{Ti}_{3} \mathrm{O}_{12}: \mathrm{Er}_{x}$ powders with $x=0,2,4,6$ and $8 \mathrm{~mol} \%$, were synthesised by the sol-gel-hydrothermal process using tetrabutyl titanate (TBT), bismuth (III) chloride ( $\mathrm{BiCl}_{3}$, Aldrich) and erbium (III) chloride hexahydrate, $99,9 \%\left(\mathrm{ErCl}_{3}\right.$, Aldrich) as starting materials.

In a procedure, solution A containing $1 \mathrm{~mL}$ of TBT (97\%) was diluted with $8.5 \mathrm{~mL}$ of ethanol for 10 min to form a white solution, which was added dropwise at $60{ }^{\circ} \mathrm{C}$ for $3 \mathrm{~h}$ with stirring to solution $\mathrm{B}$, which contained $1 \mathrm{~mL}$ of $\mathrm{HNO}_{3}$ in $40 \mathrm{~mL}$ of deionised water. An aqueous solution $\mathrm{C}$ was prepared by dissolving $\mathrm{BiCl}_{3} \cdot 6 \mathrm{H}_{2} \mathrm{O}$ in $1 \mathrm{~mL}$ of $\mathrm{HCl}$, and solution $\mathrm{D}$ was prepared by dissolving $\mathrm{ErCl}_{3}$ in $2 \mathrm{~mL}$ of deionised water.

To prepare the $\mathrm{Bi}_{4-x} \mathrm{Ti}_{3} \mathrm{O}_{12}: \mathrm{Er}_{x}$ precursor, solutions $\mathrm{C}$ and $\mathrm{D}$ were added dropwise to solution $\mathrm{B}$. Under stirring and $\mathrm{N}_{2}$ bubbling, $\mathrm{NaOH} 10 \mathrm{M}$ was added to the bismuth erbium titanium solution, and a white, homogeneous colloidal bismuth erbium titanium slurry was formed.

The mixed solution was transferred to a $500 \mathrm{~mL}$ Teflon-lined stainless steel reactor, sealed and then heated at $180{ }^{\circ} \mathrm{C}$ for $48 \mathrm{~h}$ under a partial oxygen pressure of 30 bar. At the end of the reaction, the autoclave was cooled down to room temperature. The as-synthesised white powder, attached to the Teflon container, was collected, centrifuged, washed with distilled water and ethanol to remove any remaining ions and dried at $60{ }^{\circ} \mathrm{C}$ for $6 \mathrm{~h}$ under atmospheric pressure. 


\subsection{Characterization}

Er-doped BIT powders were structurally characterised by X-ray diffraction (XRD). Data were acquired using a Siemens Advanced D-8 diffractometer with $\mathrm{CuK}_{\alpha}$ radiation at $40 \mathrm{kV}$ and $30 \mathrm{~mA}$. Raman spectra were recorded on a WITEC model CRC200, using a $5.5 \mathrm{~mW}$ laser with a wavelength of $514.5 \mathrm{~nm}$ with a grating of 1200 groove/mm. Surface morphological analysis of BIT nanoparticles were carried out by scanning electron microscopy (FEI Quanta 650F Environmental SEM). The UC spectra were obtained by exciting with a $980 \mathrm{~nm}$ and $1480 \mathrm{~nm}$ laser (Alcatel $1933 \mathrm{SMG}$ ) with a maximum power of $50 \mathrm{~mW}$. The laser was focused on the samples using a lens with a focal length of $30 \mathrm{~mm}$. The emitted light was collected using a lens with focal length $50 \mathrm{~mm}$ and focused on the entrance slit of a CCD spectrograph (Andor Shamrock 303i).

The luminescence decay curves were obtained by exciting with a 10 ns pulsed optical parametric oscillator laser (EKSPLA/NT342/3/UVE) and the emission was focused in the entrance of the spectrograph coupled to a photomultiplier (R928 Hamamatsu in the Vis range or 5509-73 Hamamatsu for the NIR range) and recorded using a digital storage oscilloscope (Tektronix 2430).

\section{Results and discussion}

\subsection{XRD patterns}

Fig. 1 shows the XRD patterns of the BIT and Er-doped BIT samples. As shown in Fig. 1 the sharp and well-defined peaks reveal high crystallinity for all of the as-prepared Er-doped BIT powders, which were not submitted to any heat treatment.

The XRD Bragg reflection was assigned by using an orthorhombic perovskite structure (space group Fmmm, JCPDS card no 56-0814) of BIT at room temperature. The peak associated with the (117) plane of BIT and Er-doped BIT shows the highest intensity, indicating that all sample compositions conform to the bismuth layered structure with $m=3$. The results are in agreement with earlier observations reporting that the strongest diffraction corresponds to the $\left(11_{2 m+1}\right)$ reflection in the Aurivillius phase for bismuth layered structured ferroelectrics compositions [33].

Fig. 2 displays the XRD patterns of BIT and Er-doped BIT in the $28-30^{\circ} 2 \Theta$ range for all of the samples. 
The effect of Er-substitution on the BIT structure can be seen in the clear shifting of the (1 117 ) reflection. Fig. 2 shows the X-ray diffraction patterns of BIT and the BIT-doped phases. The shift of the strongest diffraction peak $(h k l)$ is closely related to the ionic radii of $\mathrm{Er}^{3+}, \mathrm{Bi}^{3+}$ and $\mathrm{Ti}^{4+}$. According to Shannon et al. [34], the ionic radii are $1.03 \AA$ for $\mathrm{Bi}^{3+} ; 0.88 \AA$ for $\mathrm{Er}^{3+}$ and $0.605 \AA$ for $\mathrm{Ti}^{4+}$. When $\mathrm{Er}^{3+}$ replaces $\mathrm{Bi}^{3+}$ in the structure, the difference in the ionic radii leads to a decrease in the lattice parameters and the cell volume (Table 1), this is observed by shift of the XRD peak (117) to higher angles as shown in Fig. 2. To further evaluate the variation of the crystal structure the lattice parameters were calculated and shown in Table 1. The Rietveld refinement showed that all the crystal structures converged to the tetragonal phase, i.e. $a=b$ (see Table 1). While it is well-known that BIT shows the tetragonal phase at temperatures above $675^{\circ} \mathrm{C}$, Hirata et al. found that there is no obvious changing in XRD pattern for tetragonal and orthorhombic phases [35]. This is because the ratio of $a$ - and $b$-axis varies very close to 1 with $a / b=0.993$ [1], 0.9835 [35], 0.985 [36], 1.008 [37], 1.011 [38], 1.006 [39] and 0.993 [40].

In addition, $\mathrm{Du}$ et al. reported the presence of a stable tetragonal phase at room temperature in nanoparticles $[40,41]$. The origin of this stabilization was attributed to the surface energy mechanism. Due to the very high specific surface area of the nanoparticles, an excess surface energy per unit volume is created. Then, this excess of surface energy contributes differentially to the relative free energies of the tetragonal and orthorhombic phases, leading to the stabilization of the tetragonal phase at room temperature [41]. Their observations suggested that the critical particle size to stabilize this phase is below $40 \mathrm{~nm}[40,41]$.

Taking into account this effect, we estimated an average particle size using the (117) diffraction peak and the Scherrer equation given by:

$$
d=k \lambda /(\beta \cos (\theta))
$$

where $d$ is particle size, $k \sim 1$ is the shape factor, $\lambda=0.1540 \mathrm{~nm}$ is the wavelength of the $\mathrm{CuK}_{\alpha}$ radiation, $\beta$ is the full-width at half-maximum (FWHM) and $\theta$ is the diffraction angle [42]. The averaged particle size, the peak position and the FWHM are displayed in the Table 1.

As shown in Table 1, the lattice parameters, $a, b$ and $c$, decrease with increasing $\mathrm{Er}^{3+}$ content. The variations of lattice parameters and cell volume can be ascribed to the substitution of large-ion-radius $\mathrm{Bi}^{3+}$ ions by smaller $\mathrm{Er}^{3+}$ ions in the BIT lattice. 
The lattices parameter obtained from XRD are in very close agreement with a pseudo-tetragonal phase found by Hirata et al with $a=b \approx \sqrt{2} a_{T}$ with $a_{T}=3.85 \AA$ being the lattice parameter of the hightemperature tetragonal phase [35].

\begin{tabular}{c|c|c|c|c|c}
\hline & \multicolumn{5}{|c}{ Erbium content in $\mathrm{Bi}_{4-\mathrm{x}} \operatorname{Er}_{\mathrm{x}} \mathrm{Ti}_{3} \mathrm{O}_{12} \mathrm{~mol} \%$} \\
\hline Lattices parameters $(\AA)$ & $0 \%$ & $2 \%$ & $4 \%$ & $6 \%$ & $8 \%$ \\
\hline$a$ & 5.42707 & 5.42164 & 5.41723 & 5.41849 & 5.41895 \\
$b$ & 5.42707 & 5.42164 & 5.41723 & 5.41849 & 5.41895 \\
$c$ & 32.64568 & 32.62741 & 32.53729 & 32.71974 & 32.36215 \\
\hline Volume $\left(\AA^{3}\right)$ & 961.5161 & 959.056 & 954.7196 & 960.6527 & 950.3152 \\
Particle size $(\mathrm{nm})$ & 32.7 & 21.5 & 29.4 & 17.2 & 21.9 \\
\hline
\end{tabular}

Table 1. Lattice parameters and crystallite sizes of BIT and Er-doped BIT.

\subsection{Raman spectra}

As mentioned previously, the BIT structure is composed of $\left(\mathrm{Bi}_{2} \mathrm{Ti}_{3} \mathrm{O}_{10}\right)^{2-}$ perovskites units embedded between two bismuth oxides layers $\left(\mathrm{Bi}_{2} \mathrm{O}_{2}\right)^{2+}$ along the c-axis. In the perovskite units, Ti atoms are surrounded by oxygen octahedrons, and $\mathrm{Bi}$ atoms occupy the outside of $\mathrm{TiO}_{6}$ octahedrons[43]. In our case, this behaviour can be explained by the existence of three types of substitution of Er ions for Bi ions in BIT. Er ions can substitute for Bi ions $(i)$ in the perovskite units only (A sites of the pseudoperovskite blocks), (ii) in the $\mathrm{Bi}_{2} \mathrm{O}_{2}$ layers only, or (iii) in both. A Raman spectroscopic study was done to determine the substitution sites of Er atoms in BIT and structural changes of $\mathrm{TiO}_{6}$ octahedrons.

The room temperature Raman spectra the BIT and Er-doped BIT samples are shown in Fig. 3. Raman selection rules for pseudo-orthorhombic BIT with space group Fmmm allow 24 active optical modes of different symmetries $\left(6_{\mathrm{Ag}}+2 \mathrm{~B}_{1 \mathrm{~g}}+8 \mathrm{~B}_{2 \mathrm{~g}}+8 \mathrm{~B}_{3 \mathrm{~g}}\right)[44,45]$. However, as shown in Fig. $3 a$, only 11 Raman modes were observed, which is partially due to the possible overlap of vibrations and the broadening or weak features of some bands.

It has been reported that different ferroelectric orderings can be derived from the orthorhombic structure in BIT [44]. Thus, BIT prepared by diverse methods and chemical routes show variation on the local structures relating to ferroelectric orderings, which results in the differences in the Raman spectra of BIT. The Raman spectrum of the BIT sample (Fig. $3 a$ ) is similar to those obtained for nanoparticles of pure BIT in previous studies [46]. The spectra exhibit intense phonon modes at about 285, 470 and 490 $\mathrm{cm}^{-1}$, together with some weak modes. The characteristic modes can be labelled according to the 
assignments of Graves et al. [47]. The Raman modes in the range 200-400 $\mathrm{cm}^{-1}\left(\mathrm{~B}_{2 \mathrm{~g}}+\mathrm{B}_{3 \mathrm{~g}}\right.$ modes$)$ have been ascribed to O-Ti-O. A major mode at $470-490 \mathrm{~cm}^{-1}$ has been assigned to the split between $\mathrm{B}_{2 \mathrm{~g}}$ and $\mathrm{B}_{3 \mathrm{~g}}$ modes and described as a Ti-O torsional mode. A band feature at $651 \mathrm{~cm}^{-1}$ exhibits Ag character and has been associated with the $\mathrm{Ti}-\mathrm{O}$ symmetric stretch. According to the symmetry of $\mathrm{TiO}_{6}$, the mode at $258 \mathrm{~cm}^{-1}$ is Raman inactive and can be observed when distortion occurs into octahedron. The mode at $336 \mathrm{~cm}^{-1}$ arises from a combination of stretching and bending vibrations. Some phonon modes, e.g., at $322 \mathrm{~cm}^{-1}, 542 \mathrm{~cm}^{-1}, 651 \mathrm{~cm}^{-1}$ and $859 \mathrm{~cm}^{-1}$, appear wide and weak because of the considerable distortion in the $\mathrm{TiO}_{6}$ octahedral and hence these phonon modes may induce stresses in crystalline BIT. The appearance of modes at 285, 542 and $859 \mathrm{~cm}^{-1}$ suggests the presence of perovskite structure[18]. In general, our results in the formation of BIT are in agreement with previously published results, even although some differences exist in relation to the mode counting in the polycrystalline material, due to possible symmetry breaking, low peak intensity and overlap of vibration modes [18,28].

Fig. $3 b$ shows that with an increasing Er content ( $2 \mathrm{~mol} \%)$, the Raman scattering peaks exhibit a strong decrease in intensity and become broader. A marked shift to higher frequencies and a broadening of the linewidth (FWHM) were observed as the Er concentration increased. This behaviour increases for samples with 4, 6 and $8 \mathrm{~mol} \%$, as shown in Fig. $3 c, d$ and $e$.

The vibrational modes of Er-doped BIT can be classified as the internal modes of $\mathrm{TiO}_{6}$ octahedra and the lattice transition involved in the motion of the cations in the pseudo-perovskite slabs and the $\mathrm{Bi}_{2} \mathrm{O}_{2}$ layers. For the Er-doped BIT, it was reported that the mode at about $60 \mathrm{~cm}^{-1}$ is due to the displacement of $\mathrm{Bi}^{3+}$ ions in $\mathrm{Bi}_{2} \mathrm{O}_{2}$ layers, and that those at 77 and $120 \mathrm{~cm}^{-1}$ are related to the vibration of the ions in the A sites of the pseudo-perovskite blocks [48]. In general, these modes become increasingly diffuse and broad with increasing Er content, implying the active participation of the A-site in the substitution process[18]. In our case, the reduction of the intensity of these modes with increasing Er content, suggests that the incorporation of $\mathrm{Er}^{3+}$ does not occur mainly at the A-site in the pseudo-perovskite blocks.

In metal oxides with $\mathrm{MO}_{6}$ octahedral symmetry $(\mathrm{M}=\mathrm{Ti}, \mathrm{Ta}, \mathrm{Nd}, \mathrm{Zr}, \mathrm{Cu}$, etc.), the intra-group energy binding is large compared with the inter-group or crystal binding energy. Therefore, to a first approximation, the internal mode description is suitable for the interpretation of the Raman modes 
originating from the $\mathrm{Ti}-\mathrm{O}$ bond. A perfect 'isolate' $\mathrm{TiO}_{6}$ octahedron has six vibrational modes: $\mathrm{A}_{1 \mathrm{~g}}, \mathrm{E}_{\mathrm{g}}$, $F_{1 u}, F_{1 u}, F_{2 g}$ and $F_{2 u}[49]$, where, $A_{1 g}, E_{g}$ and $F_{2 g}$ are Raman active, $F_{1 u}$ and $F_{1 u}$ are infrared active, and $\mathrm{F}_{2 \mathrm{u}}$ is silent. With the lowering of the symmetry of $\mathrm{TiO}_{6}$ octahedron inside the BIT nanocrystal, all of selection rules are broken, and all these vibrational modes can become Raman active with various intensities. The modes observed at 589 and $869 \mathrm{~cm}^{-1}$ clearly have $\mathrm{A}_{1 \mathrm{~g}}$ character due to the pure stretching mode of $\mathrm{TiO}_{6}$ octahedra. This mode remains unchanged with Er substitution, so the Er does not substitute for Ti, only for $\mathrm{Bi}$. The 518 and $544 \mathrm{~cm}^{-1}$ modes can be assigned to $\mathrm{B}_{2 \mathrm{~g}}$ and $\mathrm{B}_{3 \mathrm{~g}}$, which come from the splitting of an $E_{\mathrm{g}}$ mode. This $\mathrm{E}_{\mathrm{g}}$ mode, involving opposing excursions of the external apical oxygen atoms of the octahedral, is two-fold degenerate for a tetragonal-like cell [24]. It splits into two components, $\mathrm{B}_{2 \mathrm{~g}}+\mathrm{B}_{3 \mathrm{~g}}$, with pseudo-orthorhombic distortion. All of these changes show that the substitution of $\mathrm{Er}$ for $\mathrm{Bi}$ in perovskite layer causes an increase in the symmetry of $\mathrm{TiO}_{6}$ octahedron and a decrease in pseudo-orthorhombic distortion.

On the other hand, Zhu et al. have reported the dependence between the crystal structure, phase transition and grain sizes of 23,42 and $53 \mathrm{~nm}$ for $\mathrm{Bi}_{4} \mathrm{La}_{\mathrm{x}} \mathrm{Ti}_{3} \mathrm{O}_{12}$ nanocrystals [49]. The results showed that $\mathrm{La}$ substitution for Bi strengthens the short-range interaction between the atoms, decreases orthorhombic distortion and leads to a ferroelectric-paraelectric phase transition at the critical La content for the BIT nanocrystals. This effect is increased with decreasing grain size $(23 \mathrm{~nm})$. Our result shows similar behaviour to those reported by the authors, considering the particle size of our samples.

Fig. 4 shows the SEM micrographs of the BIT and Er-doped BIT samples. It is clearly seen that the nanoparticles in Fig. 4a, c and e, $(x=0,4$ and $8 \mathrm{~mol} \%)$ are nearly spherical with a diameter range of 0.5, 0.2 and $0.25 \mu \mathrm{m}$ respectively. As shown in Fig. $4 \mathrm{~b}$ and $\mathrm{d}(\mathrm{x}=2$ and $6 \mathrm{~mol} \%)$, the plate-like primary powders have agglomerate size bigger than $5 \mu \mathrm{m}$. When the micro-plates are overlapped on top of each other, the bottom plate could be clearly seen through the upper plate, indicating that the plate-like primary particles are considerably small. The agglomeration process was attributed to Van der Waals forces. Particles have a tendency to form agglomerates, in order to reduce surface free energy in BIT nanocrystals. In Fig. $4 f$ the EDX result shows that the sample only contains the elements $\mathrm{Bi}, \mathrm{Ti}, \mathrm{O}$ and Er. 


\subsection{Up-conversion photoluminescence spectra}

The up-conversion photoluminescence (UC) emission spectrum of Er-doped BIT nanoparticles as a function of the wavelength is shown in the Fig. $5 a$. The UC spectrum was measured at an exciting wavelength of $1480 \mathrm{~nm}$. The synthesized samples show a strong emission in the near infrared around $\sim 980 \mathrm{~nm}$ and a weak band of red emission at $\sim 666 \mathrm{~nm}$, which are assigned to the ${ }^{4} \mathrm{I}_{11 / 2} \rightarrow{ }^{4} \mathrm{I}_{15 / 2}$ and ${ }^{4} \mathrm{~F}_{9 / 2} \rightarrow{ }^{4} \mathrm{I}_{15 / 2}$ ion $\mathrm{Er}^{3+}$ transitions, respectively [18,50]. As displayed in Fig. 5a, the intensity of UC emission processes increases as the $\mathrm{Er}^{3+}$ ion concentration increases, reaching a maximum at $6 \mathrm{~mol} \%$. After that, the luminescence intensity decreases rapidly due to the greater amount $\mathrm{of}^{\mathrm{E}^{3+}}$ ions and the shorter distance among them, thus favouring energy transfer through non-radiative processes between the ions. The photoluminescence spectrum (Fig. $5 b$ ) was measured at an exciting wavelength of $473 \mathrm{~nm}$. The nanoparticles exhibit a strong green emission between 529 and $553 \mathrm{~nm}$ and a weak emission at 666 nm red corresponding to the transitions ${ }^{2} \mathrm{H}_{11 / 2},{ }^{4} \mathrm{~S}_{3 / 2} \rightarrow{ }^{4} \mathrm{I}_{15 / 2}$ and ${ }^{4} \mathrm{~F}_{9 / 2} \rightarrow{ }^{4} \mathrm{I}_{15 / 2}$, respectively. The maximum intensity is reached for the sample doped at $4 \mathrm{~mol} \%$.

There are several mechanisms to describe the UC process. The easiest way to populate the upper levels is through successive absorption of two or more photons by the ground state absorption (GSA), followed by excited-state absorption (ESA) processes. Another way to populate these levels is by energy transfer between neighbour activator ions [51].

To better understand the mechanism involved in this process, the decay curve of the emission ${ }^{4} \mathrm{I}_{11 / 2} \rightarrow{ }^{4} \mathrm{I}_{15 / 2}$ was measured. A quick rise of the intensity with a lifetime ( $\tau$ ) around $\tau \sim 0.11-0.22 \mathrm{~ms}$ is observed followed by a rapid decrease with a longer lifetime of $\tau \sim 1 \mathrm{~ms}$, as displayed in Fig. 7. This means that two photons of $1480 \mathrm{~nm}$ are successively absorbed by the material and the ${ }^{4} \mathrm{I}_{9 / 2}$ level is populated immediately. Then, because of the small energy difference, the ${ }^{4} \mathrm{I}_{9 / 2}$ level decays nonradiatively to ${ }^{4} \mathrm{I}_{11 / 2}$ level. After that, the emission is generated and decays to the ground state ${ }^{4} \mathrm{I}_{15 / 2}$. This process is consistent with the GSA/ESA mechanism explained above. The diagram of the mechanism of the up-conversion processes for the emission is shown in Fig. 8. 


\section{Summary and conclusions}

Different samples of Er-doped $\mathrm{Bi}_{4} \mathrm{Ti}_{3} \mathrm{O}_{12}$ (BIT) were prepared by a combined sol-gel hydrothermal method. The hydrothermal reactions were carried out under a partial oxygen pressure of $30 \mathrm{bar}$. XRD patterns confirm that $\mathrm{Er}^{3+}$ replaces $\mathrm{Bi}^{3+}$ in the structure at all concentrations investigated. The increasing mol\% of Er leads to a decrease in the lattice parameters and the cell volume, and shows an average of the grain size of approx. $25 \mathrm{~nm}$. We found that the small size of the nanoparticles stabilized a tetragonal phase at room temperature with lattice parameter $a=b \approx \sqrt{2} a_{T}$.

Raman spectra showed that the Er substitution by Bi (4, 6 and $8 \%$ mol) does not occur mainly at the Asite in the pseudo- perovskite blocks because the characteristic modes disappear with increasing Er concentration. Instead, the substitution occurs mainly in the $\mathrm{Bi}_{2} \mathrm{O}_{2}$ layers.

The UC photoluminescence of Er-doped BIT nanoparticles showed a strong emission in the near infrared $(980 \mathrm{~nm})$ and a weak band of red emission $(666 \mathrm{~nm})$. The maximum emission is obtained at $6 \mathrm{~mol} \%$. The decay curve of the infrared emission indicated two interaction zones: $(i)$ a quick rise of the intensity with a lifetime ranging $\tau \sim 0.11-0.22 \mathrm{~ms}$ and, then, (ii) a decrease with a longer lifetime of $\tau \sim 1 \mathrm{~ms}$. This means that two photons of $1480 \mathrm{~nm}$ are successively absorbed by the material and the ${ }^{4} \mathrm{I}_{9 / 2}$ level is populated immediately, then, because of the small energy difference, the ${ }^{4} I_{9 / 2}$ level decays nonradiatively to ${ }^{4} \mathrm{I}_{11 / 2}$ level. The photoluminescence spectrum showed that nanoparticles exhibit a strong green emission between 529 and $553 \mathrm{~nm}$ and a weak emission red at $666 \mathrm{~nm}$. In this case, the maximum emission was obtained for $4 \mathrm{~mol} \%$.

\section{Acknowledgments}

We gratefully acknowledge financial support by Proyecto Basal CEDENNA FB0807 and Proyecto Anillo ACT 1204. E.C.A. fruitfully acknowledges financial support by the Deutsche Forschungsgemeinschaft, DFG, Germany, [Grants No. Ja821/4 within SPP 1386 (Nanostructured Thermoelectric Materials) and No. Ja821/7-1 within SPP 1538 (Spin Caloric Transport)]. We thank Prof. C. M. Sotomayor Torres from Catalan Institute of Nanoscience and Nanotechnology (ICN2) for the SEM Images. 


\section{References}

[1] B. Aurivillius, Mixed Bismuth Oxides with Layer Lattices; II, Structure of $\mathrm{Bi}_{4} \mathrm{Ti}_{3} \mathrm{O}_{12}$, Ark. Für Kemi. 1 (1949) 199-512.

[2] E.. Subbarao, A family of ferroelectric bismuth compounds, J. Phys. Chem. Solids. 23 (1962) 665-676.

[3] A.Z. Simões, C.S. Riccardi, L.S. Cavalcante, E. Longo, J.A. Varela, B. Mizaikoff, D.W. Hess, Ferroelectric fatigue endurance of $\mathrm{Bi}_{4-x} \mathrm{La}_{\mathrm{x}} \mathrm{Ti}_{3} \mathrm{O}_{12}$ thin films explained in terms of $\mathrm{x}$-ray photoelectron spectroscopy, J. Appl. Phys. 101 (2007) 084112.

[4] Y. Shimakawa, Y. Kubo, Y. Nakagawa, S. Goto, T. Kamiyama, H. Asano, F. Izumi, Crystal structure and ferroelectric properties of $\mathrm{ABi}_{2} \mathrm{Ta}_{2} \mathrm{O}_{9}(\mathrm{~A}=\mathrm{Ca}, \mathrm{Sr}$, and $\mathrm{Ba})$, Phys. Rev. B. 61 (2000) $6559-6564$.

[5] J. Hou, Y. Qu, D. Krsmanovic, C. Ducati, D. Eder, R. V. Kumar, Hierarchical assemblies of bismuth titanate complex architectures and their visible-light photocatalytic activities, J. Mater. Chem. 20 (2010) 2418.

[6] Y. Noguchi, M. Miyayama, Defect control and properties in bismuth layer structured ferroelectric single crystals, in: S. Priya, S. Nahm (Ed.), Lead-free piezoelectrics, Springer New York, New York, NY, 2012: pp. 405-459.

[7] D. Peng, X. Wang, C. Xu, X. Yao, J. Lin, T. Sun, Bright upconversion emission, increased Tc, enhanced ferroelectric and piezoelectric properties in Er-doped $\mathrm{CaBi}_{4} \mathrm{Ti}_{4} \mathrm{O}_{15}$ multifunctional ferroelectric oxides, J. Am. Ceram. Soc. 96 (2013) 184-190.

[8] F.H. Wee, F. Malek, A.U. Al-Amani, F. Ghani, Effect of two different superstrate layers On bismuth titanate (BiT) array antennas, Sci. Rep. 4 (2014).

[9] U. Al-Amani, W. Krengvirat, A.F. Mohd Noor, K. Abd., S. Sreekant, Sintering and characterization of rare earth doped bismuth titanate ceramics prepared by soft combustion synthesis, in: A. Lakshmanan (Ed.), Sintering ceramics - New Emerging Techniques, InTech, 2012: pp. 357-378.

[10] Y. Shimakawa, Y. Kubo, Y. Tauchi, H. Asano, T. Kamiyama, F. Izumi, Z. Hiroi, Crystal and electronic structures of $\mathrm{Bi}_{4-\mathrm{x}} \mathrm{La}_{\mathrm{x}} \mathrm{Ti}_{3} \mathrm{O}_{12}$ ferroelectric materials, Appl. Phys. Lett. 79 (2001) 2791.

[11] F. Miao, B. Tao, P.K. Chu, Synthesis, microstructure, and electronic band structure properties of nanocrystalline neodymium-doped bismuth titanate ferroelectric films fabricated by the sol-gel method, Mater. Res. Bull. 61 (2015) 238-244.

[12] B.H. Park, B.S. Kang, S.D. Bu, T.W. Noh, J. Lee, W. Jo, Lanthanum-substituted bismuth titanate for use in non-volatile memories, Nature. 401 (1999) 682-684.

[13] J.S. Kim, S.S. Kim, Ferroelectric properties of Nd-substituted bismuth titanate thin films 
processed at low temperature, Appl. Phys. A. 81 (2005) 1427-1430.

[14] P. Du, L. Luo, W. Li, Q. Yue, H. Chen, Optical temperature sensor based on upconversion emission in Er-doped ferroelectric $0.5 \mathrm{Ba}\left(\mathrm{Zr}_{0.2} \mathrm{Ti}_{0.8}\right) \mathrm{O}_{3}-0.5\left(\mathrm{Ba}_{0.7} \mathrm{Ca}_{0.3}\right) \mathrm{TiO}_{3}$ ceramic, Appl. Phys. Lett. 104 (2014) 152902.

[15] V. Lojpur, G. Nikolić, M.D. Dramićanin, Luminescence thermometry below room temperature via up-conversion emission of $\mathrm{Y}_{2} \mathrm{O}_{3}: \mathrm{Yb}^{3+}, \mathrm{Er}^{3+}$ nanophosphors, J. Appl. Phys. 115 (2014) 203106.

[16] L.F. Johnson, Comments on materials for efficient infrared conversion, Appl. Phys. Lett. 15 (1969) 48.

[17] F. Auzel, Upconversion and anti-Stokes processes with $\mathrm{f}$ and $\mathrm{d}$ ions in solids, Chem. Rev. 104 (2004) 139-174.

[18] R. Bokolia, O.P. Thakur, V.K. Rai, S.K. Sharma, K. Sreenivas, Dielectric, ferroelectric and photoluminescence properties of $\mathrm{Er}^{3+}$ doped $\mathrm{Bi}_{4} \mathrm{Ti}_{3} \mathrm{O}_{12}$ ferroelectric ceramics, Ceram. Int. 41 (2015) 6055-6066.

[19] H.W. Zheng, S.J. Liu, G.S. Yin, W.C. Wang, C.L. Diao, Y.Z. Gu, W.F. Zhang, Strong up conversion photoluminescence in $\mathrm{Er}^{3+}$ doped $\mathrm{Bi}_{4} \mathrm{Ti}_{3} \mathrm{O}_{12}$ ferroelectric materials prepared by solgel method, J. Sol-Gel Sci. Technol. 59 (2011) 290-296.

[20] L. Wang, W. Ma, Y. Fang, Y. Zhang, M. Jia, R. Li, Y. Huang, $\mathrm{Bi}_{4} \mathrm{Ti}_{3} \mathrm{O}_{12}$ synthesized by high temperature solid phase method and it's visible catalytic cctivity, Procedia Environ. Sci. 18 (2013) 547-558.

[21] L. Kong, J. Ma, W. Zhu, O.. Tan, Preparation of $\mathrm{Bi}_{4} \mathrm{Ti}_{3} \mathrm{O}_{12}$ ceramics via a high-energy ball milling process, Mater. Lett. 51 (2001) 108-114.

[22] W.L. Liu, H.R. Xia, H. Han, X.Q. Wang, Structural and dielectrical properties of bismuth titanate nanoparticles prepared by metalorganic decomposition method, J. Cryst. Growth. 269 (2004) 499-504.

[23] Y. Chen, Z. Pen, Q. Wang, J. Zhu, Crystalline structure, ferroelectric properties, and electrical conduction characteristics of W/Cr co-doped $\mathrm{Bi}_{4} \mathrm{Ti}_{3} \mathrm{O}_{12}$ ceramics, J. Alloys Compd. 612 (2014) $120-125$.

[24] X.-C. Zheng, G.-P. Zheng, Z. Lin, Z.-Y. Jiang, Thermal and dynamic mechanical analyses on $\mathrm{Bi}_{0.5} \mathrm{Na}_{0.5} \mathrm{TiO}_{3}-\mathrm{BaTiO}_{3}$ ceramics synthesized with citrate method, Ceram. Int. 39 (2013) 12331240.

[25] M. Anilkumar, S.R. Dhage, V. Ravi, Synthesis of bismuth titanate by the urea method, Mater. Lett. 59 (2005) 514-516. 
[26] P. Pookmanee, S. Phanichpant, Characterization of lead-free bismuth titanate $\left(\mathrm{Bi}_{4} \mathrm{Ti}_{3} \mathrm{O}_{12}\right)$ synthesized by a modified oxalate co-precipitation method, J. Ceram. Process. Res. 10 (2009) 448.

[27] H. Gu, Z. Hu, Y. Hu, Y. Yuan, J. You, W. Zou, The structure and photoluminescence of $\mathrm{Bi}_{4} \mathrm{Ti}_{3} \mathrm{O}_{12}$ nanoplates synthesized by hydrothermal method, Colloids Surfaces A Physicochem. Eng. Asp. 315 (2008) 294-298.

[28] Q. Yang, Y. Li, Q. Yin, P. Wang, Y.-B. Cheng, $\mathrm{Bi}_{4} \mathrm{Ti}_{3} \mathrm{O}_{12}$ nanoparticles prepared by hydrothermal synthesis, J. Eur. Ceram. Soc. 23 (2003) 161-166.

[29] Y. Shi, C. Cao, S. Feng, Hydrothermal synthesis and characterization of $\mathrm{Bi}_{4} \mathrm{Ti}_{3} \mathrm{O}_{12}$, Mater. Lett. 46 (2000) 270-273.

[30] K.-T. Kim, C.-I. Kim, D.-H. Kang, I.-W. Shim, The effect of Eu substitution on the ferroelectric properties of $\mathrm{Bi}_{4} \mathrm{Ti}_{3} \mathrm{O}_{12}$ thin films prepared by metal-organic decomposition, Thin Solid Films. 422 (2002) 230-234.

[31] J. Hou, R. V. Kumar, Y. Qu, D. Krsmanovic, Controlled synthesis of photoluminescent $\mathrm{Bi}_{4} \mathrm{Ti}_{3} \mathrm{O}_{12}$ nanoparticles from metal-organic polymeric precursor, J. Nanoparticle Res. 12 (2010) 563-571.

[32] D. Thomazini, M.V. Gelfuso, J.A. Eiras, Microwave assisted hydrothermal synthesis of $\mathrm{Bi}_{4} \mathrm{Ti}_{3} \mathrm{O}_{12}$ nanopowders from oxide as raw materials, Powder Technol. 222 (2012) 139-142.

[33] Z. Peng, Q. Chen, Y. Chen, D. Xiao, J. Zhu, Microstructure and electrical properties in W/Nb co-doped Aurivillius phase $\mathrm{Bi}_{4} \mathrm{Ti}_{3} \mathrm{O}_{12}$ piezoelectric ceramics, Mater. Res. Bull. 59 (2014) 125130.

[34] R.D. Shannon, Revised effective ionic radii and systematic studies of interatomic distances in halides and chalcogenides, Acta Crystallogr. Sect. A. 32 (1976) 751-767.

[35] T. Hirata, T. Yokokawa, Variable-temperature X-ray diffraction of the ferroelectric transition in Bi4Ti3O12, Solid State Commun. 104 (1997) 673-677.

[36] E.C. Subbarao, Ferroelectricity in $\mathrm{Bi}_{4} \mathrm{Ti}_{3} \mathrm{O}_{12}$ and its solid solutions, Phys. Rev. 122 (1961) 804807.

[37] A.D. Rae, J.G. Thompson, R.L. Withers, A.C. Willis, Structure refinement of commensurately modulated bismuth titanate, $\mathrm{Bi}_{4} \mathrm{Ti}_{3} \mathrm{O}_{12}$, Acta Crystallogr. Sect. B Struct. Sci. 46 (1990) 474-487.

[38] R.W.G. Wyckoff, The Structure of Crystals, vol. 3, Interscience Publishers, 1951.

[39] J.F. Dorrian, R.E. Newnham, D.K. Smith, M.I. Kay, Crystal structure of $\mathrm{Bi}_{4} \mathrm{Ti}_{3} \mathrm{O}_{12}$, Ferroelectrics. 3 (1972) 17-27. 
[40] Y. Du, J. Fang, M. Zhang, J. Hong, Z. Yin, Q. Zhang, Phase character and structural anomaly of $\mathrm{Bi}_{4} \mathrm{Ti}_{3} \mathrm{O}_{12}$ nanoparticles prepared by chemical coprecipitation, Mater. Lett. 57 (2002) 802-806.

[41] Y.L. Du, M.S. Zhang, Q. Chen, Z. Yin, Investigation of size-driven phase transition in bismuth titanate nanocrystals by Raman spectroscopy, Appl. Phys. A Mater. Sci. Process. 76 (2003) 1099-1103.

[42] A.L. Patterson, The Scherrer formula for X-ray particle size determination, Phys. Rev. 56 (1939) 978-982.

[43] A. Hushur, J.-H. Ko, S. Kojima, S.S. Lee, M.-S. Jang, Raman scattering study of A- and B-site substitutions in ferroelectric $\mathrm{Bi}_{4} \mathrm{Ti}_{3} \mathrm{O}_{12}$, J. Korean Phys. Soc. 41 (2002) 763-768.

[44] H. Idink, V. Srikanth, W.B. White, E.C. Subbarao, Raman study of low temperature phase transitions in bismuth titanate, $\mathrm{Bi}_{4} \mathrm{Ti}_{3} \mathrm{O}_{12}$, J. Appl. Phys. 76 (1994) 1819.

[45] E. Kroumova, M.I. Aroyo, J.M. Perez-Mato, A. Kirov, C. Capillas, S. Ivantchev, H. Wondratschek, Bilbao crystallographic server: Useful databases and tools for phase-transition studies, Phase Transitions. 76 (2003) 155-170.

[46] S. Kojima, R. Imaizumi, S. Hamazaki, M. Takashige, Raman scattering study of bismuth layerstructure ferroelectrics, Jpn. J. Appl. Phys. 33 (1994) 5559-5564.

[47] P.R. Graves, G. Hua, S. Myhra, J.G. Thompson, The Raman modes of the aurivillius phases: temperature and polarization dependence, J. Solid State Chem. 114 (1995) 112-122.

[48] Y. González-Abreu, A. Peláiz-Barranco, Y. Gagou, J. Belhadi, P. Saint-Grégoire, Vibrational analysis on two-layer Aurivillius phase $\mathrm{Sr}_{1-\mathrm{x}} \mathrm{Ba}_{\mathrm{x}} \mathrm{Bi}_{2} \mathrm{Nb}_{2} \mathrm{O}_{9}$ using Raman spectroscopy, Vib. Spectrosc. 77 (2015) 1-4.

[49] K. Zhu, M.-S. Zhang, Y. Deng, J. Zhou, La content and size effects on crystal structure and phase transition of $\mathrm{Bi}_{4-x} \mathrm{La}_{\mathrm{x}} \mathrm{Ti}_{3} \mathrm{O}_{12}$ nanocrystals, Phys. B Condens. Matter. 405 (2010) 1388-1393.

[50] D. Peng, H. Zou, C. Xu, X. Wang, X. Yao, Er doped $\mathrm{BaBi}_{4} \mathrm{Ti}_{4} \mathrm{O}_{15}$ multifunctional ferroelectrics: Up-conversion photoluminescence, dielectric and ferroelectric properties, J. Alloys Compd. 552 (2013) 463-468.

[51] D.R. Gamelin, H.U. Gudel, Upconversion processes in transition metal and rare earth metal systems, in: H. Yersin (Ed.), Transition metal and rare earth compounds: excited states, transitions, interactions II, Springer Berlin Heidelberg, Berlin, Heidelberg, 2001: pp. 1-56. 